\title{
TRANSITIONING STUDENTS FROM SIMULATION MECHANICS TO SIMULATION AS A PROCESS IMPROVEMENT TOOL: A MULTIMEDIA CASE STUDY APPROACH
}

\author{
Scott R. Schultz \\ Department of Mechanical and Industrial Engineering \\ Mercer University \\ 1400 Coleman Avenue \\ Macon, GA 31207, U.S.A.
}

\author{
Christopher D. Geiger \\ Department of Industrial Engineering and Management \\ Systems \\ 4000 Central Florida Boulevard \\ University of Central Florida \\ Orlando, FL 32816, U.S.A.
}

\begin{abstract}
Many undergraduate Industrial Engineering programs offer a course in discrete event simulation. While students often grasp the theory behind simulation and can perform the mechanics of model building and analysis, they often have difficulty formulating creative, viable process improvement ideas, which is a need of today's industrial employers. In this paper, a novel multimedia case-based teaching approach is presented that addresses this need. These multimedia cases are presented as course learning modules to the students. The components of the casebased learning modules include not only the requisite problem background, summary and relevant data, but they also include additional streaming video of the real-world process being studied, actual engineering drawings and still photos of the product and process, and a base simulation model. It is these additional components of the proposed multimedia teaching approach that help "bring the factory to the student" and better prepare graduates for the national workforce.
\end{abstract}

\section{INTRODUCTION}

Most undergraduate Industrial Engineering programs throughout the US and the world offer a course in computer simulation, more specifically, discrete event simulation. In practice and in research, industrial engineers typically use simulation to analyze complex industrial or service systems to identify process improvement strategies to enhance system performance. These strategies may include changing staffing levels, investing in additional capital equipment, revising operating policies, etc. Today's competitive, highly integrative business environment has created a demand for competent engineers who can integrate technical, managerial and systems skills. In particular, engineers need enhanced capabilities to deal with more complex design challenges and to generate creative, viable solutions in often vaguely defined problem environments.

By our observations, there are two general approaches to teaching simulation. One approach primarily emphasizes simulation theory and concepts. This includes teaching students the role and proper use of probability and statistics, data modeling, random variate generation, design of experiments, and statistical interpretation of model performance. The other approach emphasizes a hands-on approach that teaches the mechanics of simulation and model building. This usually involves using a commercially-available simulation tool to develop models, run simulations, and analyze results (Altiok et al. 2001).

While there are advocates for each approach, and even a combination of these approaches, students taught under these practices frequently exhibit a lack of understanding of how to improve a system after they have learned to construct a model of that system, run simulations, and analyze the output. From our teaching experience, we frequently ask students to develop a model, analyze the system, and suggest process improvements. Most students are capable of correctly developing the model and analyzing the results; however, only a few tend to suggest viable improvements to the system under study. Possible reasons for this failure to generate process improvement ideas include:

- Students have not been exposed to many kinds of industrial and service systems, so their repertoire of practical solutions is limited;

- Students focus mainly on the mechanics of building the simulation model and often believe the problem is solved once the simulation is debugged and running; or

- Students are not provided with adequate exercises or discussions about how to interpret simulation results and what actions to take to improve system performance. 


\section{Schultz and Geiger}

The problem then is to help students transition from the focus of constructing computer simulation models and analyzing results to identifying root causes and developing creative, effective ways to improve the system. This need is also recognized in general terms by the 2003-2004 Accreditation Board for Engineering and Technology general criteria for basic level engineering programs, specifically the following parts of Criterion 3 (Program Outcomes and Assessment): "Engineering programs must demonstrate that their graduates have:

(b) an ability to design and conduct experiments, as well as to analyze and interpret data,

(e) an ability to identify, formulate, and solve engineering problems,

(k) an ability to use the techniques, skills, and modern engineering tools necessary for engineering practice" (ABET 2002, pg. 5).

We propose an innovative multimedia teaching approach that uses case-based learning modules that emphasize system design and process improvement. These multimedia learning modules will serve as a supplement to the undergraduate discrete event simulation course. The aim of these modules is to shift the students' focus from building simulation models to using simulation as a design and process improvement tool. The learning modules consist of a case-based study guide that focuses on process improvement and a working simulation model of the current system. The uniqueness of the proposed methodology is that the multimedia component of the learning modules includes multiple representations and views of the system under study. It is richly documented with engineering data, diagrams, video footage, animation, etc. of the actual industrial setting, essentially bringing the factory to the student.

\section{PREVIOUS RELATED LITERATURE}

The proposed teaching approach of simulation builds on previous research on engineering education. First, the learning modules are case-based. Richards et al. (1995), for example, describe how both cases and learning modules promote active learning, and how they have been used successfully in engineering education for many years. Pang and Hodson (1999) state that effective learning is significantly enhanced through the use of cases because students can easily relate to specific personal experiences over abstractions. Second, the learning modules use examples of systems and processes actually used in industry. Shore and Plager (1978) call for the use of realworld cases in simulation education. Standridge (2000) and Standridge (2001) discuss a case approach to digital simulation that uses active learning techniques in a computer-aided teaching studio.
The proposed multimedia learning module approach not only builds upon but goes beyond previous efforts by adding a uniquely-designed multimedia component. Some similar projects have been successful in integrating multimedia and collaborative approaches to learning. These projects focused primarily on concepts related to product development and manufacturing rather than process improvement. Nott, Nott and Lee (2000) introduce an interactive CD-ROM that requires students to use Taylor II process simulation software to model and analyze real-life applications. However, no literature considers integrating real-world information (e.g., product and process drawings, video footage of the industrial process, etc.) in a multimedia format to teach simulation.

\section{THE MULTIMEDIA LEARNING MODULES}

The proposed learning module consists of three primary multimedia tools. These tools are hypertext markup language web pages, streaming video, and discrete event simulation models.

\subsection{Hypertext Web Pages}

The web pages present the learning module and case study instructional material. The web pages also provide a structure for the student. The first of several web pages is a brief introduction that describes the purpose of the learning module and instructions on how to navigate through the case study. All web pages are similar in format. Each page has a common set of hyperlinks in the left-hand column and a unique set of information or instructions in the body.

In addition to the introductory web page, the learning module includes the following case study instructional web pages:

- Problem Background - provides a brief description of the production environment, the products, and the general production process. The description includes pictures of the products and drawings of each product's parts and subcomponents.

- Process Description - provides a detailed description of the production system and process steps. The description includes an overhead engineering drawing to help students visualize the actual process.

- $\quad$ Problem Statement - describes management concerns/issues regarding the current system.

- $\quad$ Process Data - provides details of relevant process data such as processing time distributions, setup time distributions, number of available resources, shift schedules, rework percentages, product routing data, etc.

- Production Schedule - describes the production schedule of the system. 


\section{Schultz and Geiger}

- $\quad$ Student Assignment - describes the students' assignment with links to all proposed improvement scenarios. Each scenario describes a general process improvement idea and includes data relevant to the idea including cost assumptions and the impact of this improvement on process data. While these are the proposed ideas, students are not limited to this set of improvement scenarios.

\subsection{Streaming Video}

As the saying goes, "a picture is worth a thousand words." One of the key features of this learning module is a short streaming video of the process. We emphasize in our classes that the only way to really understand a process is by spending time with it, watching and observing. The video allows the students to visit the industrial environment of the system under study virtually.

The streaming video is a one-minute clip of the system in operation. The video in effect shows all the steps in the production process. The purpose of the video is to provide the students with an actual view of the process. The video is not meant to be used to collect data. All pertinent data are provided either in the case study instructional web pages, the base simulation model or the proposed process improvement scenarios.

\subsection{Simulation Model}

The third tool of the learning module is the base simulation model. Recall that the emphasis of this multimedia learning module is not only system design but also process improvement. We, therefore, provide a simulation model of the base (current) system. This model is provided for three reasons. The base model:

1. shifts a student's focus from building the model to using the model for process improvement;

2. provides the student with a new perspective on learning how to embellish an existing model; and

3. introduces new simulation constructs and modeling strategies, which the student will need to investigate before they can fully understand all facets of the model.

The students are expected to review the web pages describing the system and problem, view the video footage, and complete each of the assignment improvement scenarios. To complete a scenario, the students must modify the base simulation model, perform a series of experiments, and report the results. The students then make final process improvement recommendations, justifying those recommendations.

\section{ASSESSMENT OF THE LEARNING MODULES AND STUDENT LEARNING OUTCOMES}

The multimedia learning module summarizing an actual real-world problem is given to students in an introductory simulation and modeling course. This introductory course should teach the fundamentals of simulation, and how to develop models using some simulation application. The case study is presented with minimal explanation from the instructor. The instructor only demonstrates to the students in the class how to access the introductory web page of the learning module. The reason for the minimal guidance is to determine if the proposed multimedia case study is developed such that the students can understand the intent of the study and complete the study with no additional instruction.

Upon completion of the case study, the students complete a survey to assess learning outcomes and their overall opinion of the multimedia learning module. The survey questions cover three primary categories: multimedia, simulation modeling, and process improvement.

In the multimedia section, students are asked several questions that relate to their understanding of the real-world problem environment through their experience using the multimedia tools provided for the case study. They respond to each question using a scale of 1 to 5 with 1 being the lowest. In the simulation modeling section of the survey, the students are asked questions that attempt to assess their understanding of the base simulation model's logic. Finally, in the process improvement section of the survey, the students indicate if the case study helped enhance their understanding of how simulation could be used as a process improvement tool. The students are also asked what would help improve their ability to generate process improvement ideas.

\section{PILOT TESTING OF THE MULTIMEDIA LEARNING MODULES}

We pilot tested the proposed multimedia case study approach in an actual undergraduate introductory discrete event simulation course with an enrollment of 21 junior Industrial Engineering and Industrial Management students at Mercer University. The case study was given during week 10 of the 15 -week Spring semester.

The case study for the learning module describes the assembly of wood and glass doors for entertainment centers manufactured at a furniture plant. Interested readers can access this particular learning module at < http: / / faculty.mercer.edu/schultz_sr/cou rses/ise403/casestudy/index.html>. Examples of the instructional web pages for the door assembly case study are provided in Appendix A of this paper.

Door assembly is a sequential three-step operation consisting of gluing and piecing together the side rails, end rails and panels; clamping and nailing the assembly; and mudding and stacking the doors on a pallet. Figure 1 is a diagram of the door assembly process flow. 


\section{Schultz and Geiger}

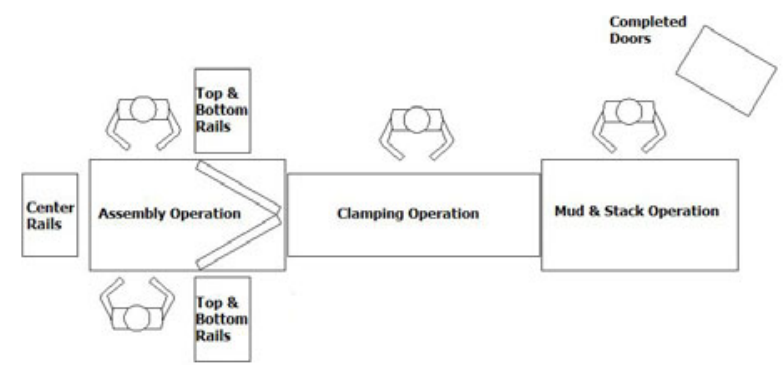

Figure 1: Door Assembly Process Flow Diagram

More than 30 different types of doors are produced in this operation with varying levels of complexity. Production is determined by a build schedule.

For door assembly, the process is currently taking 10 hours a day, where setup between batches is a significant portion of the total assembly time. Management asserts that the assembly line should be able to produce the schedule within the normal 7.6 hour shift.

A base simulation model of the current process is constructed using Rockwell Software's Arena ${ }^{\circledR}$. The logic of the model is somewhat complex and contains two primary sections. One section models the production schedule and setup process. The other section models the three process steps for assembling the doors. An animation of the assembly process is also provided and includes performance measures such as total setup time, doors per hour, and door counts by type.

The students are to consider three modifications to the process. The first modification considers releasing an assembly operator to begin an early setup. The second modification adds an additional part-time operator to eliminate the setup time by setting up a parallel operation. The final modification allows the students to analyze the impact of using alternate production schedules.

\subsection{Assessment of the Proposed Multimedia Case Study Teaching Approach}

A total of 16 students completed the survey. A partial listing of questions from the multimedia section and average scores based on a scale of 1 to 5 are given in Table 1 .

Table 1: Partial List of Survey Questions and Associated Student Responses

\begin{tabular}{lc}
\hline Survey Question & Avg Response \\
\hline $\begin{array}{l}\text { Were the process descriptions helpful } \\
\text { in understanding the process? }\end{array}$ & 4.1250 \\
$\begin{array}{l}\text { Were the layout drawings helpful in } \\
\text { understanding the process? }\end{array}$ & 4.0625 \\
\hline $\begin{array}{l}\text { Were the product drawings helpful in } \\
\text { understanding the process? }\end{array}$ & 3.8125 \\
\hline Was the video helpful? & 4.0625 \\
\hline
\end{tabular}

In the modeling section of the survey, the most telling question is "Were you able to understand the model's logic?" Table 2 summarizes the responses by percentage of students. It can be seen that a modest $43 \%$ of the students felt that they could at least understand most of the model logic by week 10 of the course.

Table 2: Student Response Percentages for the Question "Were you able to understand the model's logic?"

\begin{tabular}{lc}
\hline Response & \% of Student Respondents \\
\hline Yes & 18.75 \\
Mostly & 25.00 \\
Some & 37.50 \\
No & 18.75 \\
\hline
\end{tabular}

In the process improvement section of the survey, $100 \%$ of the students indicated that the case study helped enhance their understanding of how simulation could be used as a process improvement tool. The students were also asked what would help improve their ability to generate process improvement ideas. Most responded that additional case studies of "real-life" problems using this multimedia approach would help. In addition, the students indicated that more discussion in class about process improvement ideas would strengthen this ability. A final question on the survey was "Should the instructor develop additional multimedia case studies?" All students indicated "Yes."

Some general conclusions that can be drawn from the comments provided by the students are:

- The simulation model logic is a little more advanced than the average student was ready for at that stage (week 10) in the course. To address this, we could consider presenting this case study later in the semester, or perhaps provide a case requiring less complex model logic;

- Having the instructor in the classroom during the case study would have greatly helped the class overcome some initial hurdles in the model logic;

- The multimedia approach was well-received, and additional case studies are requested;

- Some students were comfortable with process improvement before the case study, but the case study definitely helped; and

- Students requested additional real-world case studies to help improve their understanding and experience with process improvement.

\section{SUMMARY AND CONCLUSIONS}

Discrete event simulation is taught in many undergraduate Industrial Engineering programs throughout the world. Students typically gain a general understanding of the theory behind simulation and the mechanics for developing a model and analyzing results. This paper proposes a means 


\section{Schultz and Geiger}

to take simulation instruction one step further. A novel multimedia case-based learning module teaching approach that emphasizes process improvement simulation is proposed. The modules consist of three primary components: (1) a web-based case study guide, (2) actual information about the real-world industrial system described in the case study, and (3) a simulation model of the base system. The actual information included uses multiple representations and views of the system and its process steps (e.g., engineering drawings, video footage of the system in operation, etc.) in a case study format, an approach that has not been explored previously in teaching industrial simulation.

The multimedia learning module teaching approach is pilot tested and the preliminary results are quite promising. This new approach of embedding real-world information and data of the actual process in a case study format was well-received by the students. Furthermore, based on the in-class feedback and survey responses, the students benefited from using the learning modules in that the modules improved their ability to generate creative process improvement strategies.

Our next steps are to use the general conclusions drawn from the student comments and from future course offerings to improve the components of the multimedia learning modules to increase their effectiveness and educational benefit. Our goal is to continue to help shift the student's focus from using simulation as a model building and data analysis exercise to using simulation as a process improvement tool.

\section{ACKNOWLEDGMENTS}

We want to recognize Mercer University Industrial Engineering Bachelor of Science degree graduates Aaron Lachmann and George Rogers for assisting with the development of the web pages, streaming video and simulation models for the door assembly multimedia case study. We also would like to thank Kelly Carter of Mercer University for helping establish some of the initial ideas and themes for the multimedia case-based learning modules.

\section{APPENDIX A: SAMPLE WEB PAGES FOR THE DOOR ASSEMBLY CASE STUDY MULTIMEDIA LEARNING MODULE}

Appendix A contains two of the 12 door assembly case study instructional web pages. Figure A-1 is the introductory page that appears when opening the learning module. The hyperlinks in the left-hand column are the additional pages in the case study. Figure A-2 is the Problem Statement that presents the students with the problem under study and three possible improvement scenarios.

\section{REFERENCES}

Accreditation Board for Engineering and Technology, Inc. (ABET) 2002. Criteria for accrediting engineering programs, effective for evaluations during the 2003-2004 accreditation cycle: pg. 5.

Altiok, T., W.D. Kelton, P. L'Ecuyer, B.L. Nelson, B.S. Schmeiser, T.J. Schriber, L.W. Schruben, J.R. Wilson. 2001. Various ways academics teach simulation: are they all appropriate? In Proceedings of the 2001 Winter Simulation Conference, ed. B.A. Peters, J.S. Smith, D.J. Medeiros, and M.W. Roher, 1580-1591.

Nott C., G. Nott, C.C. Lee. 2000. Simply simulation: an interactive CD-ROM based approach for learning simulation concepts. . In Proceedings of the 2000 Winter Simulation Conference, ed. J.A. Joines, R.R. Barton, K. Kang, and P.A. Fishwick, 1699-1702.

Pang, L. and W. T. Hodson. 1999. The use of simulation in process reengineering education. In Proceedings of the 1999 Winter Simulation Conference, ed. P.A. Farmington, H.B. Nembhard, D. T. Sturrock, and G.W. Evans, 1397-1402.

Richards, L.G., M. Gorman, W.T. Scherer, and R.D. Landel. 1995. Promoting active learning with cases and instructional modules. Journal of Engineering Education, 84(5): 375-381.

Shore, B. and D. Plager. 1978. Simulation: a case approach. In Proceedings of the 1978 Winter Simulation Conference, ed. H.J. Highland, N.R. Nielsen, and L.G. Hull, 361-370.

Standridge, C.R. 2000. Teaching simulation using case studies. In Proceedings of the 2000 Winter Simulation Conference, ed. J.A. Joines, R.R. Barton, K. Kang, and P.A. Fishwick, 1630-1634.

Standridge, C.R. 2001. Teaching manufacturing systems simulation in a computer aided teaching studio. In Proceedings of the 2001 Winter Simulation Conference, ed. B.A. Peters, J.S. Smith, D.J. Medeiros, and M.W. Roher, 1613-1618. 


\section{Process Improvement Case Study \\ Door Assembly Process}

Purpose

Plant

Background

Process

Discription

Video of

Process

Problem

Statement

Process

Data

Door

Assembly

Schedule

Your

Assignment

Scenario 1

Scenario 2

Scenario 3

Simulation Model
Purpose:

- To understand a real-world problem through the use of a video based learning module

- To evaluate process improvement solutions for the problem through the use of simulation and modeling

- To recommend the best solution while supporting any conclusions

\section{Instructions:}

- Work through each link in the order that they appear on the menu to the left

- Additional instructions are given when needed in each portion of the module

Figure A-1: Introduction Web Page for the Door Assembly Case Study Learning Module 


\section{Process Improvement Case Study}

Door Assembly Process

Purpose

Plant Background

Process Discription

Video of Process

Problem Statement

Process Data

Door Assembly Schedule

Your Assignment

Scenario 1

Scenario 2

Scenario 3

Simulation Model

\section{Problem Statement}

The problem as stated earlier, is that the door assembly process is taking about 10 hours a day, and is often working 6 days a week, rather than 5 , to keep up with the cabinet room schedule. Plant management wants to determine how to improve the process so that the schedule can be accomplished in 5 days during the normal 7.6 hour shift. After observing the process, a time study was performed and the following process data was collected. Also a representative door assembly schedule was generated which represents the door demand generated by a daily cabinet room build schedule. In addition, a simulation model of the process was generated.

During the observation and time study of the process, the assembly operation itself ran smoothly. There were times when the clamp was not functioning properly, and times when the quality of the incoming parts impacted production. But in general, when the assembly team was producing parts, the workload appreared balanced and they produced at a constant and adequate rate. What became readily apparent was that the setup process was an extremely time consuming task. Since setup time is essentially non-value added from the standpoint of producing parts, reducing setup time could dramatically increase the throughput of this process.

\section{Your Assignment:}

1) Use the simulation model to analyze each of the three scenarios below to determine the impact on setup time and time to produce the schedule.

- Scenario 1 - use one of the assembly operators to begin a pre-setup

- $\underline{\text { Scenario } 2}$ - hire an operator dedicated to setup

- $\underline{\text { Scenario } 3}$ - increase the batch sizes

2) Provide a brief write up (no more than 1 page) on each scenario that includes data from the simulation to support your conclusions.

3) Make a final recommendation which gives the most cost effective solution for assembling doors during the normal shift.

Figure A-2: Problem Statement Web Page for the Door Assembly Case Study Learning Module 


\section{Schultz and Geiger}

\section{AUTHOR BIOGRAPHIES}

SCOTT R. SCHULTZ is an assistant professor in the Department of Mechanical and Industrial Engineering at Mercer University. His research interests include simulation modeling and analysis, especially with application to process improvement. He worked at Ford Motor Company for 13 years, part of which was spent applying simulation to improving manufacturing processes. $\mathrm{He}$ is a member of IIE and ASEE. His e-mail address is $<$ schultz_sr@mercer.edu> and his web address is $<$ http://faculty.mercer.edu/schultz_sr/ $>$.
CHRISTOPHER D. GEIGER is an assistant professor in the Department of Industrial Engineering and Management Systems at the University of Central Florida in Orlando, FL. His research and teaching interests include simulation modeling and analysis, machine learning in production planning and scheduling and heuristic optimization. He is a member of IIE, INFORMS and SME. His e-mail and web addresses are $<$ colgeigeremail.ucf.edu> and $<$ http://iems.ucf.edu/ver40/faculty/Gei ger. $h t m>$, respectively. 